\title{
Landscape Design: Pattern and Color in Sensory Garden for Disability Justice
}

\author{
Suci Senjana $^{1 *}$, Gian Alfa Sukarno Putra ${ }^{1}$ \\ ${ }^{1}$ Department of Architecture, Faculty of Science and Technology, UIN Maulana Malik Ibrahim Malang, Indonesia \\ * Corresponding author: ssenjana@arch.uin-malang.ac.id
}

\begin{abstract}
A responsive design to disability users is an unpopular design implementation for landscape design in Indonesia. Even space supposed to function for disability users cannot help them to have activities without obstacles. A sensory garden concept would be applied in the research to learn its impact on finding the result. Therefore, this research would propose a basic pattern and color to be used in the sensory garden. Combination of an experimental design on this design-based research and systematic review, the final output is expected to be a base pattern and color solution in proposing an inclusive landscape design. In urban development, it is essential to have an awareness of the welfare of disabled people. This research finds that applying geometric, repetitive patterns and overlaying colors on a sensory garden would increase the focus and attention of disability users with mental and physical impairments. This knowledge is not limited to being applied in a sensory garden and a landscape project design in general. This study also has the purpose of aiding practitioners in understanding an inclusive landscape design.
\end{abstract}

Keywords: Inclusive Design, Impaired User, Accessibility, Built Environment

\section{INTRODUCTION}

The fact that Indonesia has citizens with a disability is not mean that they also have the same right in a public open space. The difficulty for them is that the facility in public space is unsuitable for people with disabilities. Therefore, it is essential to study further the gap between knowledge and practitioner in applying a design concept that considers the right for everyone, even though they are not in their best condition to control their performance.

This research would seek knowledge in inclusive landscape design on a site which suppose to be used for the disability community. The site is located in the Blimbing district office of Malang City, Indonesia. It is an undeveloped green space used by disabled children for playing on the existing condition. On the current condition, the prominent users on the proposed experimental site are autistic and visual-impaired children. The office staff permits them to play and have therapy in the building as they do not have a place. The existing space needs a disability responsive space as the current hardscape is remaining unused.

It becomes a concern to have a suitable built environment that could aid them in having positive enhancement in their activities and therapy. Using a landscape design is supposed to be ideal for everyone in diverse physical and mental performance. It should be an awareness for practitioners to discover balance in those manners.

\section{LITERATURE REVIEW}

A secure built environment in a smart city should cover to protect people with all types of conditions. The term smart in planning and design should consider inclusiveness for disabled people as part of the design process in their proposal rather than an option [1]. Their condition should be seen as an aspect to look after as it is necessary to make them feel accepted by society. The 
rare and lack of action to investigate their need often produce an exclusive design that only can be used optimally for normal people [2]. Their perception of being included and accepted in a landscape design should be applied directly as they also have the right to receive and experience the same leisure as normal people [3].

In this century, the planner and designer thinking process of disability should consider their physical performance and further impact. A child with a disability could perceive a painful childhood to their adult life if people are missed to save them. Mistreated action affects their future behavior, perception, health, and social ability [4]. Besides, planning and designing an inclusive landscape describes how the impaired user will be comfortable within the environment and seeks the balance and unity between human and ecological aspects [5]. The environmental value of its natural condition should be maintained to improve user and context existing issues. The context aspect would also be mentioned in a protected landscape project, such as in the rural area. Practitioners should consider that harmonizing the surrounding with the need of disabled people is essential [6].

However, a designed landscape presents a more profound understanding rather than balancing macro elements. Whether impaired people are efficiently connected in their micro activity is also a concern. It should be accessible for them to reach the building entrance as uncomplicated as possible [7]. As we know, people have outdoor activities and have a relation with buildings and infrastructure. The most direct circulation alternative should be taken.

The accessibility design has been mentioned in general knowledge in a term called the universal design. The affirmation in this concept involves everyone as a user consideration. It means that accessibility is not limited to what we call physically impaired but looking in a broader range, including the elderly, pregnant women, and children [8]. To conclude from further literature, mainstreaming all people is not an option, but rather a list to do for the designers and planners. Practitioners should consider all possibilities of user movement ability [9][10].

This research's literature gap searches for an alternative application in sensory landscape design and perception of senses-responsive design from disability users.

\section{METHODOLOGY}

The methodology in this research is combining systematic review and design-based research. Therefore, It would propose an inclusive based-pattern based on collected site data and related knowledge. Related issues on disability users in a community open space and sensory garden would be reviewed. That knowledge was used based on the proposing new design on a site in the Blimbing district office of Malang City, Indonesia.

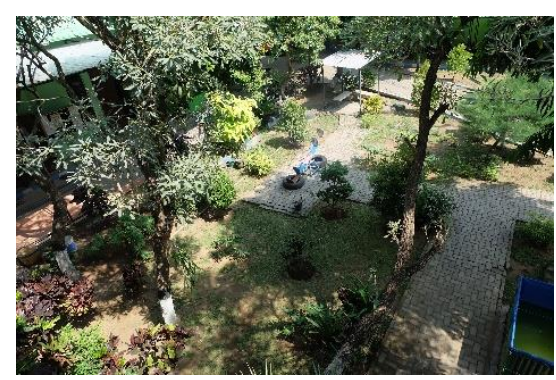

Figure 1 Existing Site.

Figure 1 shows the existing condition of the site where the disabled children used to play. The site issues were being analyzed to suggest suitable responsive design for the users. Ideally, the new design would help to enhance the relationship between site and impaired user. The proposed concept is an outcome of studying and analyzing how the user's need should be fulfilled. Their health improvement should be the main goal at the same time in the sensory garden.

The concept would be transformed into a pattern as the elements in the project; circulation, colors, and shape. The result final result is a proposed pattern for a based concept in designing an inclusive sensory garden project.

\section{RESULTS}

The site issue is the inability of context to fulfill disability responsive space for the primary users. Although they are free to move on the site, there is no facility for their activities and therapy. The sensory garden, in this research, is seen as a concept in inclusive design. It would focus on applying the proposed design, which considers the application of sight, hearing, touch, smell, and taste.

In order to apply those five senses consideration in the design, a list of sub-concepts would be proposed. However, to focus on the pattern and color, the sight aspect's result would be the main focus of this research. First, it should be a concern to position zones in the response of their mobility. Second, the experimental design proposed what color would enhance the positive effect of their therapy. The users' happiness cannot be measured directly, but the design should have awareness of this aspect. Third, landscape elements, hardscape, and softscape should also relate to the points above. 


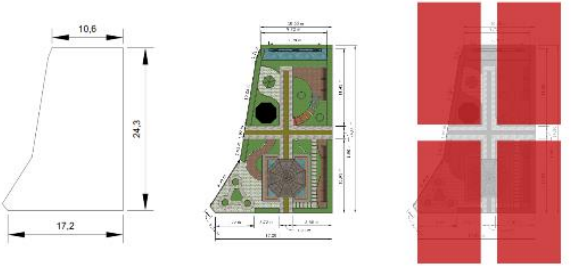

Figure 2 Geometric Zone Pattern.

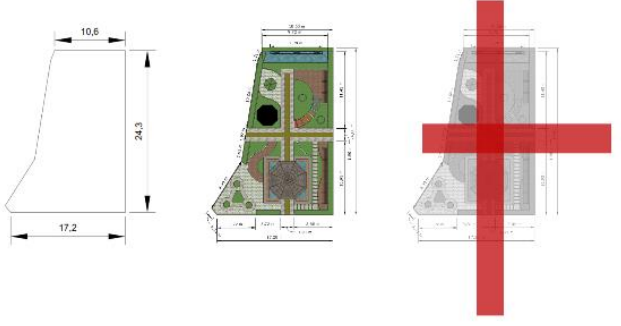

Figure 3 Geometric Circulation Pattern.

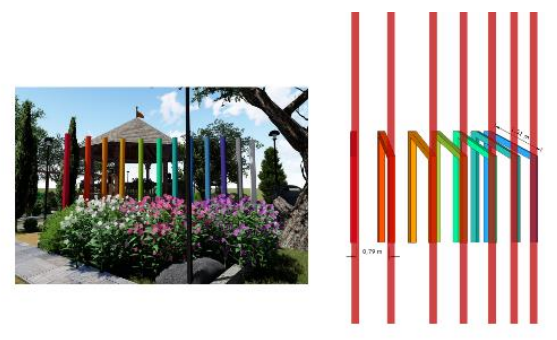

Figure 4 Repetition in Landscape Element Pattern.

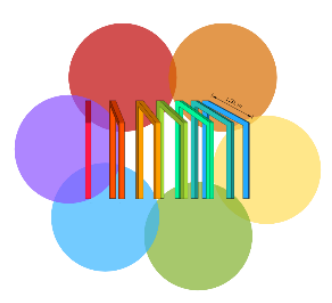

Figure 5 Overlaying Colors.

The result of experimenting with the design to obtain a final pattern in Figures 1, 2, 3, and 4 shows that geometric shapes and lines repetition would be the final finding. A study illustrates that the combination of geometrical planes and each element's repetition would attract autistic spectrum disorder children to focus longer. They tend to spend a long time and stay while seeing those types of objects. It is also stated that this pattern could aid in discovering if a child has a risk for autistic [11]. For impaired users, they reach the space comfortably and faster rather than unpredicted curve circulation. The repetition shape and line are used as a direction sign to move forward. It should be clear what they will reach and which way it is. Unwanted conditions the real project is confusion for the main users in their mobility and feel that they are not left alone.

As a combination of line and shape, the pattern would suggest user reach and connect to the site efficiently. The reason is that comfortable mobility and access is considered in this research to apply an inclusive design process. Moreover, this pattern directs users' sight and activity directly to their purpose activity and space, as this pattern suggests an enhancement of focus.

Also, the second focus in the result is color choice in the design. It is not the concern to choose a specific one in the color wheel. The emphasis is on overlaying the different colors in the design. Children with autistic spectrum disorders show a progressive improvement in their learning skills while using media that overlays colors [12]. This data is used in this study to impact their therapy and activities on site. A visual-impaired people do not also for fully blind users and people who can see in a blurry sight. These patterns and colors should aid them directly moving, playing, and reaching in the designed space.

Therefore, applying those findings, a sensory garden could be proposed as a design concept focusing on how human senses involve a built environment. The senses consideration would increase the effectiveness in applying a proposed concept for disability users.

\section{DISCUSSION}

Consideration for impaired users in the inclusive landscape design is rare to be applied. This condition impacts disability users' perception, thinking, behavior, and social skill, especially children. This study's major findings are that geometric and repetitive patterns and overlaying color would increase focus and follow the direction for disability users.

This finding is necessary as practitioners should aware of their need to feel welcomed and not being excluded. Moreover, for a site like this experimental design that functions as a place for therapy, it should be arranged to focus and stay longer. This situation of a designed site that makes them feel accepted is suggested to propose a meaningful experience during their main activity.

A related study states that a sensory garden is one solution to design a landscape for people who has a disability in mobility and visual. The research suggests that ornamental vegetation and animals' usage as nature 
contribute to the sensory garden would enhance the therapeutic healing process [13]. It becomes a concern in the future regarding their health improvement, as there is a high chance that the disability users are on health control and therapy [14].

Moreover, the result of this paper, pattern and color application, is not limited to applicability in landscape design and general knowledge related to disability studies. It can aid in improving their positive condition, mentally and physically.

However, there is a limitation of this research. The real project of sensory gardens should be analyzed as it shows real disability users' activity. Also, if the interview with the users had been done, it could illustrate their feeling between inclusion and exclusion.

\section{CONCLUSION}

The importance of applying geometric, repetitive patterns and overlaying colors on a landscape design, which experimented in this study on a sensory garden, would illustrate humanity's improvement in a design. The proposed design would think and observe the feeling and well-being of disability users. This research pursues a straightforward concept that could directly be applied to practitioners in landscape design.

However, this study's literature gap is about the possibility that different types of impaired users could have mixed feelings of inclusiveness in a sensory landscape design. Moreover, there is another question if the current pandemic, the Covid-19, impacts how practitioners apply their concept in and landscape design, especially a sensory garden for disability users. The virus or unpredicted pandemic in the future could influence users on how they are positioning themselves in a built environment [15]. This global condition would also affect the practitioners, designers, and planners on how they proposed a suitable concept. There are possibilities that this gap could be proposed as future researches.

\section{REFERENCES}

[1] R. Salha, M. Jawabrah, U. Badawy, A. Jarada, A. Alastal, Towards Smart, Sustainable, Accessible and Inclusive City for Persons with Disability by Taking into Account Checklists Tools, in: Journal of Geographic Information System. 2020;12(04):348-371. DOI: https://doi.org/10.4236/jgis.2020.124022

[2] M. Jackson, Accessing the Neighbourhood: Built Environment Performance for People with Disability, in: Architecture_MPS. 2019. DOI: https://doi.org/10.14324/111.444.amps.2019v16i 1.004

[3] M. Afonina, L. Petrova, and E. Osipova, The accessible environment and inclusive leisure park for individuals with disabilities, in: Autism and Developmental Disorders Аутизм и нарушения развития, vol. 15 , no. 4 , pp. 61-68, 2017. DOI: https://doi.org/10.17759/autdd.2017150410

[4] N. Halfon, A. Houtrow, K. Larson, P. Newacheck, The Changing Landscape of Disability in Childhood. Future Child. 2012;22(1):13-42. DOI: https://doi.org/10.1353/foc.2012.0004

[5] Szaszák G, Fekete A, Kecskés T. Access to Waterfront Landscapes for Tourists Living with Disabilities. YBL Journal of Built Environment. 2017;5(1):5-13. doi:10.1515/jbe-2017-0001

[6] A. Maciejko, B. Wojtyszyn, A. Skrzypczak, Design Problems of Tourism Infrastructure for People with Disabilities in Protected Landscape Areas in Poland, in: IOP Conference Series: Materials Science and Engineering 2019;603:042048 DOI https://doi.org/10.1088/1757-899x/603/4/042048

[7] A. Pretto, Accessibility and Conservation in Contemporary Cities: A(n) (Im)possible Coupling, in: Architecture_MPS. 2019;16(1) DOI:

https://doi.org/10.14324/111.444.amps.2019v16i 1.003

[8] A. Sirel and O. Sirel, "Universal Design" Approach for the Participation of the Disabled in Urban Life, in: Journal of Civil Engineering and Architecture, vol. 12, no. 1, 2018. Available: 10.17265/1934-7359/2018.01.002. DOI: https://doi.org/10.17265/1934-7359/2018.01.002

[9] H. Alkan Meşhur and B. Yilmaz Çakmak, Universal Design in Urban Public Spaces: The Case of Zafer Pedestrian Zone / Konya -Turkey, in: Iconarp International J. of Architecture and Planning, vol. 6, no., pp. 15-40, 2018. Available: 10.15320/iconarp.2018.47.

[10] K. Smith, W. Preiser, Universal Design Handbook. New York: McGraw-Hill; 2011.

[11] K. Pierce, D. Conant, R. Hazin, R. Stoner, J. Desmond, Preference for Geometric Patterns Early in Life as a Risk Factor for Autism, in: Arch Gen Psychiatry. 2011;68(1):101. DOI: https://doi.org/10.1001/archgenpsychiatry.2010.1 13

[12] A. Ludlow, A. Wilkins, P. Heaton, The Effect of Colored Overlays on Reading Ability in Children with Autism, in: J Autism Dev Disord 
2006;36(4):507-516.

DOI: https://doi.org/10.1007/s10803-006-0090-5

[13] A. Kopeva, O. Khrapko, O. Ivanova, Landscape Organization of a Sensory Garden for Children with Disabilities, in: IOP Conference Series: Materials Science and Engineering. 2020;753:022028. DOI: https://doi.org/10.1088/1757-899x/753/2/022028
[14] H. Hussein, Z. Omar, S. Ishak, Sensory Garden for an Inclusive Society, in: Asian Journal of Behavioural Studies. 2016;1(4):33. DOI: https://doi.org/10.21834/ajbes.v1i4.42

[15] N. Megahed, E. Ghoneim, Antivirus-built environment: Lessons learned from Covid-19 pandemic, in: Sustain Cities Soc. 2020;61:102350. DOI: https://doi.org/10.1016/j.scs.2020.102350 